\title{
Effects of Natural Dust on the Performance of PV Panels in Bangladesh
}

\author{
Md.Mizanur Rahman \\ Department of EEE, University of Asia Pacific, Dhaka, Bangladesh \\ Email: mizan.eee32@yahoo.com \\ Md. Aminul Islam \\ Department of EEE, University of Asia Pacific, Dhaka, Bangladesh \\ Email: sohel_uap09@yahoo.com \\ A.H.M. Zadidul Karim \\ Department of EEE, University of Asia Pacific, Dhaka, Bangladesh \\ Email: zadidkarim@gmail.com \\ Asraful Haque Ronee \\ Department of EEE, University of Asia Pacific, Dhaka, Bangladesh \\ Email: eshan_eee@yahoo.com
}

\begin{abstract}
Energy is considered a prime agent in the generation of wealth and a significant factor in economic development. Limited fossil resources and environmental problems associated with them have emphasized the need for new sustainable energy supply options that use renewable energies. Among available technologies for energy production from solar source, photovoltaic system could give a significant contribution to develop a more sustainable energy system. Solar Panel has its wide use starting from a simple $5 \mathrm{~W}$ diode lamp to a few $\mathrm{kW}$ ac drives. A solar panel with a battery and a charge controller and other auxiliary devices like dc to ac converters constitute a Solar Home System (SHS). Solar home system (SHS) is becoming popular day by day and even poor households are now becoming interested to purchase solar home system due to its various advantages. Solar home systems (SHS) have a major problem that is low efficiency. It also decreases output day by day because of improper maintenances, effect of dust and shadow. Accumulation of dust on solar panel of solar photovoltaic (PV) system is a natural process. It was found from the study that the accumulated dust on the surface of photovoltaic solar panel can reduce the system's efficiency by up to $35 \%$ in one month .In this paper we show that the effect of dust accumulation on the solar panel naturally and how it is possible to overcome this problem.
\end{abstract}

Index Terms - Dust, Photovoltaic, Accumulation, Wiper, AT MEGA8

\section{INTRODUCTION}

Electricity generated from sunlight is called solar electricity and the process of Converting solar light into electricity is known as the photovoltaic process. In this Process direct current (DC) electricity is produced. Edmund Becquerel, a French scientist in 1839 discovered electricity due to photovoltaic effect but efficiency is low [1]. The output of Solar cell is proportional to the sunlight intensity. The application of solar energy has become wider, with the solar photovoltaic industry's combined global revenue of US\$37 billion in 2008 [2].Bangladesh is a densely populated developing country with more than 1200 people per square kilometer and the present population is about 160 million. Only $43 \%$ of the total population has the access to electricity .However, with increasing demand for electricity, especially for industrial expansion, construction and domestic uses, the supply and power generation is facing tremendous pressure and load shedding has become a common occurrence in the urban areas. So Bangladesh should also start using solar energy in the urban areas immediately to overcome the energy crisis. Solar PV systems have already made significant headway in Bangladesh like as other developing country. Recent pioneering attempts in this field have generated enthusiasm. In Bangladesh solar home system (SHS) increase rapidly because of roughly $60 \%$ population of the country does not have access to grid electricity and are mostly dependent on biomass to meet their energy requirement. It is not effective on large application but also effective on electrified to home, shop, and school e.t.c. In Bangladesh the sunlight falls directly in summer and transversely in winter. For receiving maximum solar energy in Bangladesh solar panel was tilled $23.5^{\circ}$ (sun's inclination angle with respect to ground surface in Bangladesh)[1]. Bangladesh on an average receives around $3.82-6.43 \mathrm{kwh} / \mathrm{m}^{2}$ of solar irradiation out of which around $47.3 \%$ of the energy is received at 
frequencies from visible range $(0.38<\lambda<0.78 \mathrm{~mm})$. There are also dust around us. Since the early 1960's, scientists have noticed and studied the reduction of the collectors' performance due to the pollution on a solar cells' surface. Such studies, at that time, were focused mainly on the thermal cells and the effects of dust accumulation on the mirror reflectance (Dietz 1963). Sand and soil are among the primary sources of natural degradation, among other airborne particulates, chemical weathering processes, as well as industrial carbon and other types of dirt. It also restrict the sun light fall onto the solar panel. One of the Contributing factors in the drop of efficiency of solar PV panels in Bangladesh as well as in other country is the accumulated dust on the panel. The nature of the problem may vary by geographical locations. Moreover, from 5 to $15 \%$ reduction in peak power has been obtained by varies climatic conditions, especially accumulated dust. Also, a reduction by $2.78 \%$ per day of Isc has been obtained. On the other hand, Voc has been decreased by $0.863 \%$ per day time[5]. In a study by Salim et al. [4] into dust accumulation on a solarvillage PV system near Riyadh indicated a $32 \%$ reduction in performance after eight months. Wakim [9] indicated a reduction in PV power by $17 \%$ due to sand accumulation on panels in Kuwait city after six days. Furthermore the study also indicated that the influence of dust on PV performance would be higher in spring and summer than in autumn and winter. In this paper, the influence of dirt accumulation on the efficiency of solar PV panels is assessed by using artificial materials. A constant light radiation condition is used by mean of spotlight to overcome the variation that may be experienced under the sunlight.

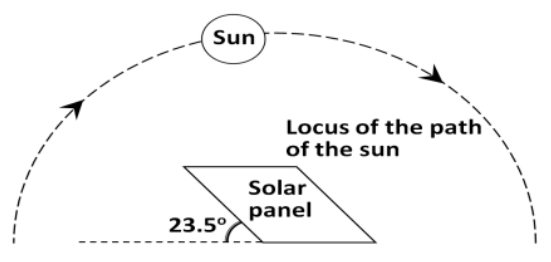

Figure 1. Sun-Earth Geometry

\section{SOLAR CELL CHARECTERSTICS}

A solar cell is a semiconductor PN junction diode, normally without an external bias, that provides electrical power to a load when illuminated. PV cells can be modeled as a current source in parallel with a diode. When there is no light present to generate any current, the PV cell behaves like a diode. As the intensity of incident light increases, current is generated by the PV cell.

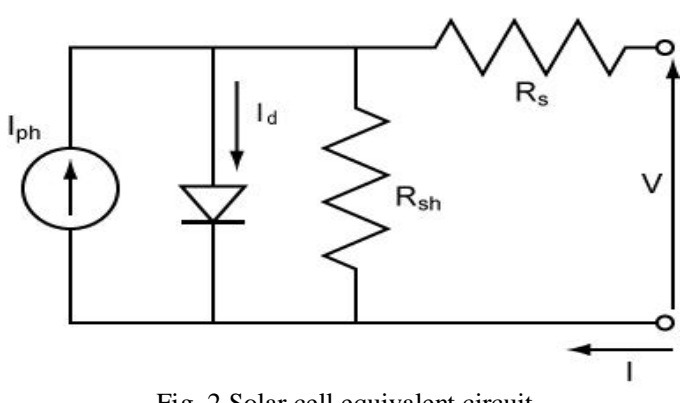

Fig. 2 Solar cell equivalent circuit

Fig. 2 shows the simplest solar cell equivalent model consists of diode and current source connected in parallel. source current is directly proportional to the solar radiation. Diode represents PN junction of a solar cell. Equation of ideal solar cell which represents the ideal solar cell model. The current equation for a solar cell is given by the following equation [4]

$\mathrm{I}=\mathrm{I}$ ph-Is $[(\mathrm{e} \mathrm{V}) /(\mathrm{m} \mathrm{VT})]-\mathrm{I}]$

where

$\mathrm{I}_{\mathrm{ph}}=$ Photo current

Is $=$ reverse saturation current

$\mathrm{V}=$ diode voltage in volt

$\mathrm{m}=$ diode ideality factor $(\mathrm{m}=1$ for ideal diode $)$

Where I ph is photo current in ampere, Is is reverse saturation current in ampere (approximately 10$8 /$ square meter), $\mathrm{V}$ is diode voltage in volt, and $\mathrm{m}$ is diode ideality factor $(\mathrm{m}=1$ for ideal diode). The intensity of incident light rays proportional with the current output from the PV panel with a nominal rise in voltage. So the performance enhancement of solar panel is related with the intensity of incident light rays which comes from the sun. The voltage-current relation for a solar cell is given by the following equation [5]:

$\mathrm{Voc}=\mathrm{kT} / \mathrm{e} \ln [\mathrm{Iph} / \mathrm{I} 01+1]$

where,

$\mathrm{V}_{\mathrm{oc}}=$ Open circuit voltage

$\mathrm{K}=$ Boltzmann constant

$\mathrm{T}=$ Temperature of the device

$\mathrm{E}=$ Element charge

$\mathrm{I}_{\mathrm{ph}}=$ Photo current

$\mathrm{I}_{01}=$ Current due to recombination due to bulk charge carriers

\section{EFFECT OF DUST ON SOLAR PANEL}

Dust consists of tiny solid particles carried by air currents. These particles are formed by disintegration which is a process of fracturing the solids into small pieces through grinding, crushing, or impact among other ways. The Mine Safety and Health Administration (MSHA) defines dust as finely divided solids that may become airborne from the original state without any chemical or physical change other than fracture. Dust is generally measured in micrometers. Dust is covered on the solar panel naturally. The layer of the dust on the solar panel increasing with the time respectively. It also 
acts as a barrier between solar panel and sun rays. There are two primary ways that dust affects the photovoltaic panels. First, dust settles directly on the solar photovoltaic panels, blocking the cells from the sun's rays. The tracing sensor may be covered by dust, inhibiting the panels from following the sun's direction (Khoshaim et al. 1983). The value of short circuit current, power decrease with respect the amount of dust on the solar panel.

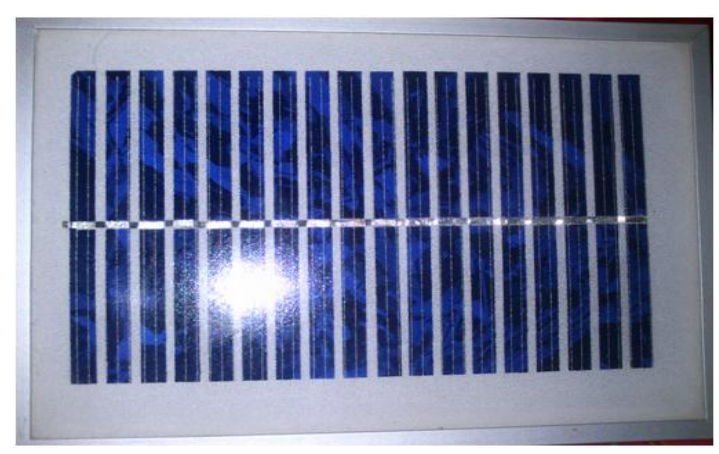

Fig. 3 Clean Solar Panel

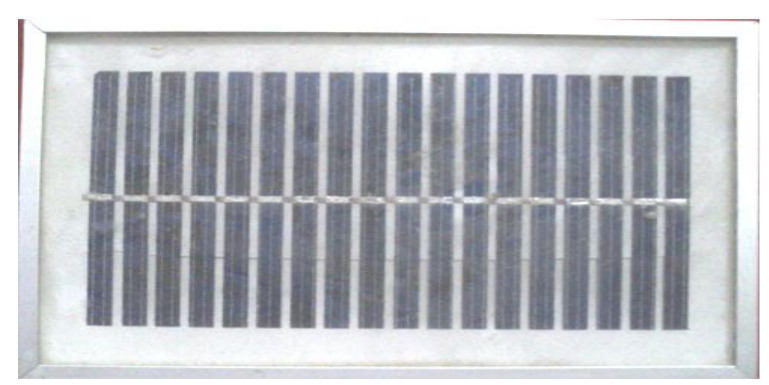

Fig. 4. Dusty Solar Panel

\section{EXPERIMENT APPARATUS AND SETUP}

Owing to the sun-earth geometry and the location of Bangladesh, the solar panel was kept inclined at an angle of 23.50 with the horizontal. The length of the panel was aligned along the north-south direction. Experiments were performed by applying natural dusts on the solar PV panel. Tests were conducted also with the clean solar PV panel in order to quantify the effects of dust on the performance of the PV panel.

The electrical specifications of the panel were as follows:

[At STC $(1000 \mathrm{~W} / \mathrm{m} 2$, AM 1.5 spectrums cell temperature $25^{\circ} \mathrm{C}$ ) nominal values]

Peak Power (Pmax) : $1 \mathrm{~W}$

Voltage (Vmp) $\quad: 8.2 \mathrm{~V}$

Current (Imp) : $0.146 \mathrm{~A}$

Open Circuit Voltage (Voc) $: 10.2 \mathrm{~V}$

Short Circuit Current (Isc) : $0.155 \mathrm{~A}$

The size of the panel used was $15.6 \mathrm{~cm} * 11 \mathrm{~cm} * 1.5 \mathrm{~cm}$.

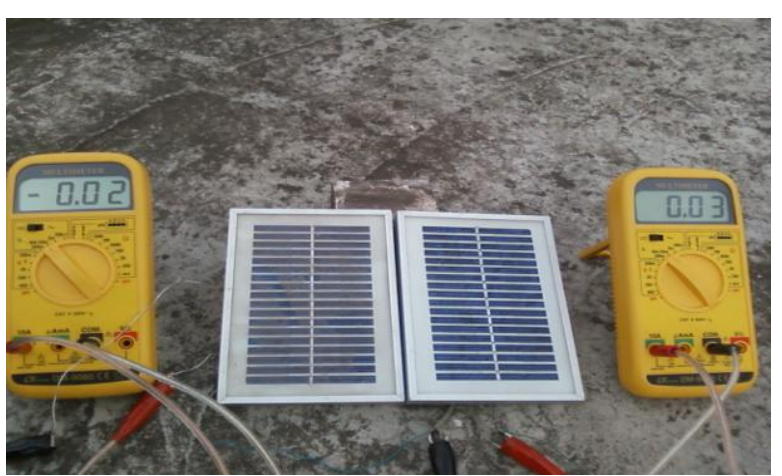

Fig. 5. Experimental Setup

Shown in Figure 5 is schematic of the experiment. Basically the system comprised a solar photovoltaic panel (rated 1W), as shown in Figure 3 . The solar panel module was made up of silicon mono-crystal cells; the system was installed and kept it at the outdoor environment for one month to achieve the amount of dust on the solar panel. The radiation energy was delivered by the sun. For the measurements of voltage and current, Lutron DM-9080 Digital multimeters were used in the arrangement as illustrated in Figure 1. In this project natural dust was used to represent the dust accumulation.. It is not a complicate study of the fundamental aspect of the dust effect.

\section{RESULT}

We consider a panel around the outside environment for one month to collect dust naturally. Then we collect data from dust and clean Solar panel with the help of multimeter. After collecting data we plot graph by the help of MATLAB software.

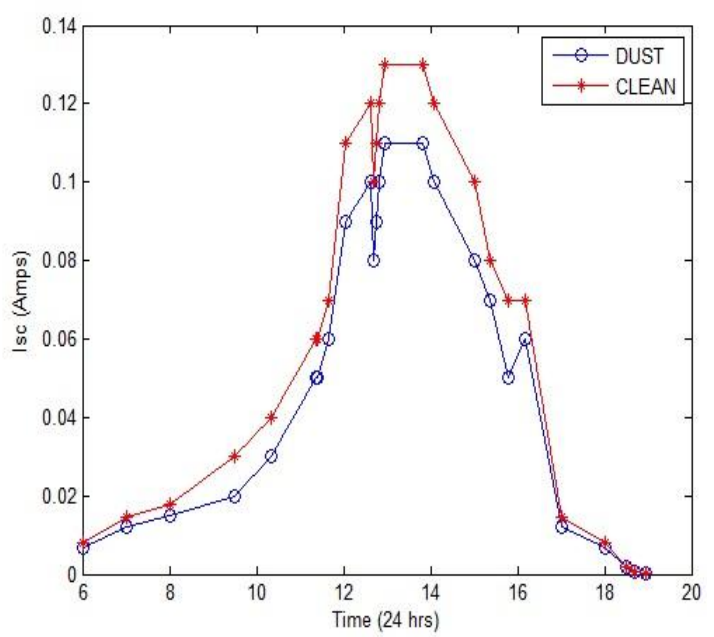

Fig.6 Graph of Isc vs Time for Dust(o) and Clean (*) panel 


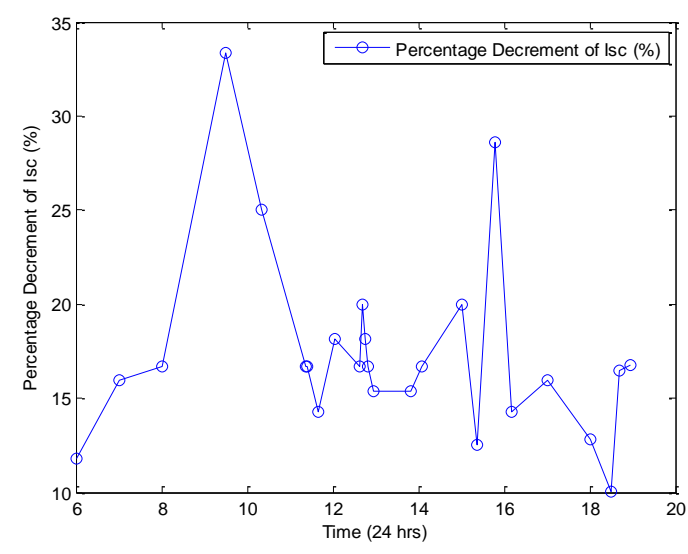

Fig.7 Graph of Percentage Decrement of Isc (\%) vs Time

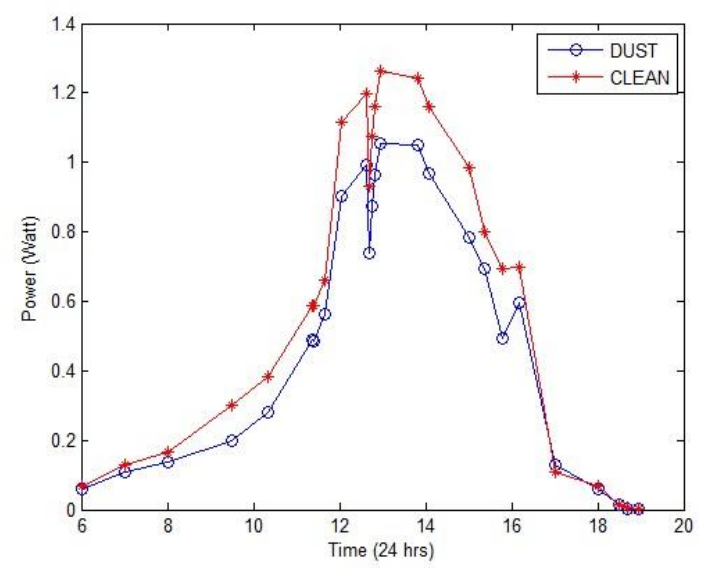

Fig.8 Graph of Isc vs Time for Dust(o) and Clean (*) panel

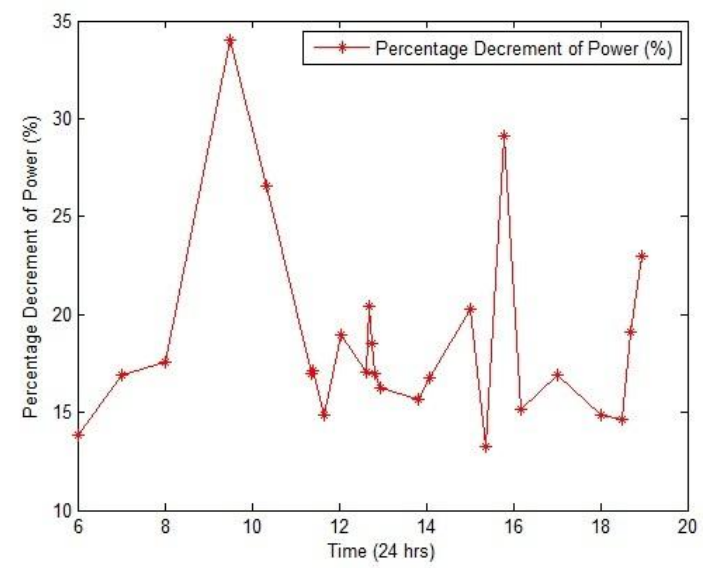

Fig.9 Graph of Percentage Decrement of Power(\%) vs Time

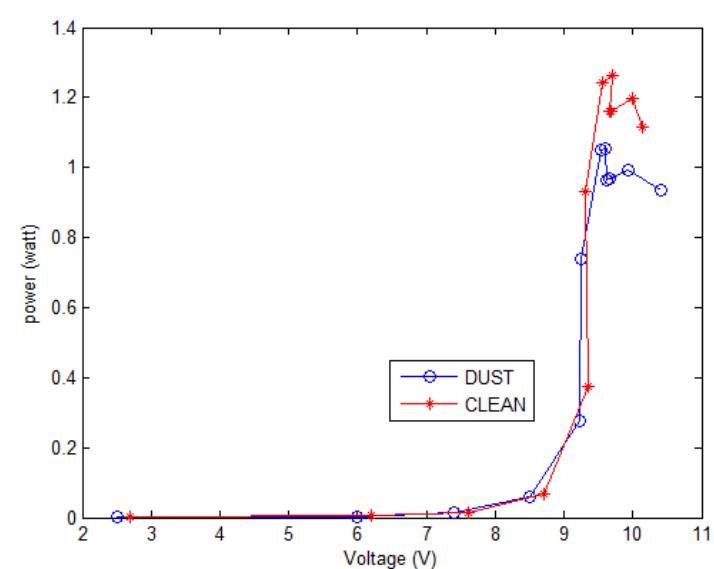

Fig.10 Graph of Power vs Time for Dust (o) and Clean (*) panel

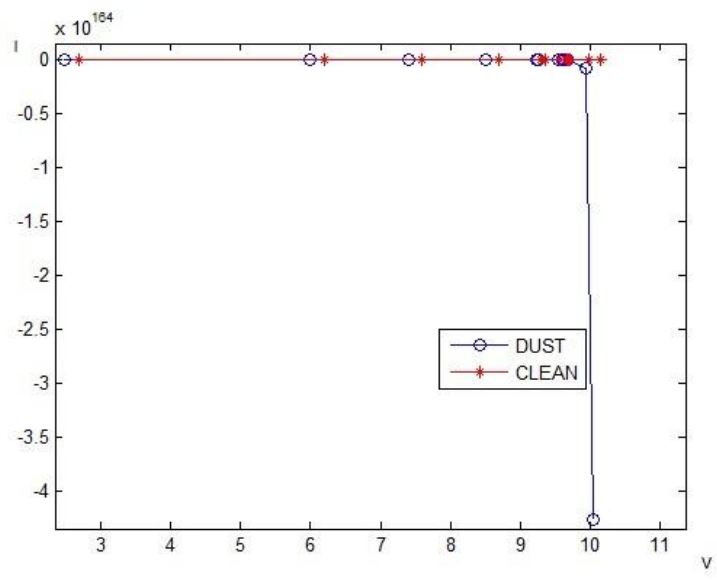

Fig.11 I-V characteristics curve for Dust(o) and Clean (*)panel

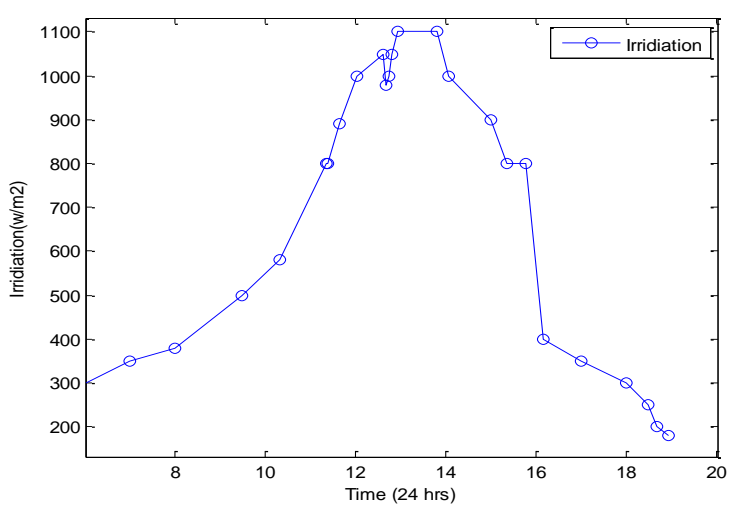

Fig 12. Graph for Irradiation vs Time

\section{COMMENT ON RESULT}

It can be easily said that the Isc of clean panel is greater than the Isc of dusty panel.when the sun intensity is lower at ( 8 am to $9 \mathrm{am})$ then the large amount percentage decrement of Isc ocuurs around $35 \%$.But at midday the amount percentage decrement of Isc is around $20 \%$. The output power of solar panel is related with short circuit current. So the percentage decrement of power as well as percentage decrement of 
Isc. From the fig. No 10 and 11 we can see that when the power of dusty panel fall then the power of clean panel does not fall. So it can be easily said that maximum point of power is reduced for dust.

\section{PROPOSED IDEA}

From the above discussion we can say that natural dust is the one of the cause to reduce the output of the solar panel. To overcome this problem we propose an idea .In our proposed idea we set a wiper on the solar panel. Every day at 5:30 A.M the wiper wipes the dust for cleaning the solar panel. Our proposed idea is a microcontroller based idea. The literature of our proposed idea with block diagram is given below.

\section{GENERAL OVERVIEW OF THE SYSTEM}

The proposed idea basically consists of five blocks as shown in figure (13). They are wiper, AVR microcontroller (ATmega8), key button, display unit, $5 \mathrm{v}$ power supply, and. A detail description of each block has given below.

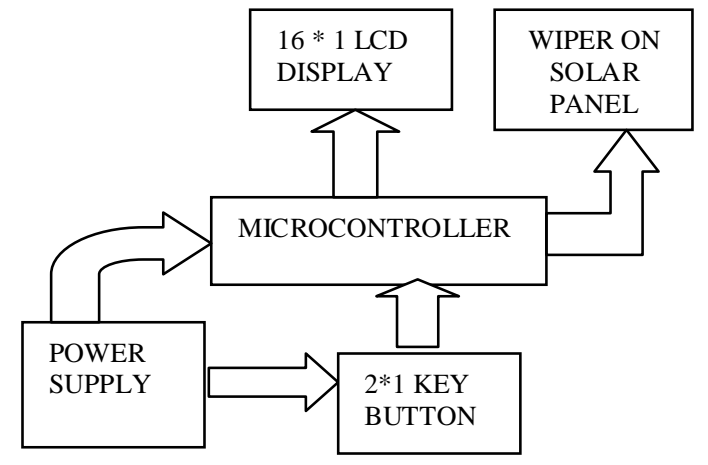

Fig 13. Block Diagram of Proposed Idea

\section{A. Wiper}

A wiper is a device used to remove rain, debris ,dust from a windscreen or windshield. Almost all motor vehicles, including trains, aircraft and watercraft, are equipped with such wipers, which are usually a legal requirement. The main element of wiper is an arm, pivoting at one end and with a long rubber blade attached to the other. The blade is swung back and forth over the glass, pushing water from its surface.

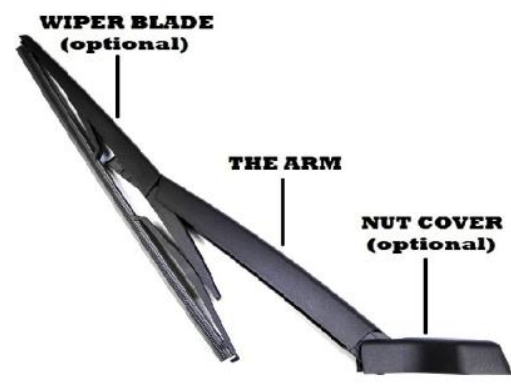

Fig 14. Wiper
The speed is normally adjustable, with several continuous speeds and often one or more "intermittent" settings. We use this wiper on the solar panel to remove the dust.

\section{B. The ATmega8 Microcontroller}

A microcontroller often serves as the "brain" of a mechatronic system. Like a mini, self-contained computer, it can be programmed to interact with both the hardware of the system and the user. Even the most basic microcontroller can perform simple math operations, control digital outputs, and monitor digital inputs. Most modern controllers have analog-to-digital converters, high-speed timers and counters; interrupt capabilities, outputs that can be pulse-width modulated, serial communication ports, etc. ATMEGA8 is one of the most popular microcontrollers used specially in automotive, industrial appliances and consumer applications. High-performance, Low-power Atmel AVR 8-bit Microcontroller. The low-power Atmel 8-bit AVR RISC-based microcontroller combines $8 \mathrm{~KB}$ of programmable flash memory, $1 \mathrm{~KB}$ of SRAM, 512K EEPROM, and a 6 or 8 channel 10-bit A/D converter. The device supports throughput of 16 MIPS at $16 \mathrm{MHz}$ and operates between 2.7-5.5 volts.

Some Key Parameters are given below

$\begin{array}{lc}\text { Parameter } & \begin{array}{c}\text { Value } \\ \text { Flash (Kbytes) }\end{array} \\ \text { Pin Count } & 32 \\ \text { Max. Operating Frequency } & 16 \mathrm{MHz} \\ \text { CPU } & 8 \text {-bit AVR } \\ \text { No of Touch Channels } & 12 \\ \text { Hardware QTouch Acquisition } & \text { No } \\ \text { Max I/O Pins } & 23 \\ \text { Ext Interrupts } & 2 \\ \text { USB Transceiver } & 0 \\ \text { Quadrature Decoder Channels } & 0\end{array}$

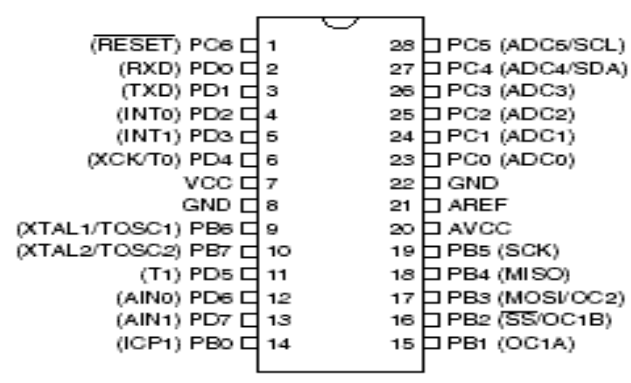

Fig 15. Pin Diagram of ATMEGA8

\section{Key Button}

We have only used three key buttons. The first button represents the control switch of the wiper is connected to PB0. The second and third buttons represents minute and hour are connected to PB1-PB2 sequentially. To prevent the debouching and to balance the current we have used resistors microcontroller pin to ground. 


\section{Display Unit}

In our project we used 16*1 LCD (Liquid crystal display). We connect the data port of LCD (D4 - D7) to microcontroller PORTC (PC2 - PC5).The RS and E pin connected to the PORTC.0 and PORTC.1 accordingly . The RW and Vss pin of LCD connected to the ground. $5 \mathrm{v}$ power supply also connected to $\mathrm{Vcc}$ pin of LCD.

\section{E. Power Supply}

For both LCD and microcontroller requires $5 \mathrm{v}$ DC supply. The power supply unit is designed which consist $230 \mathrm{v}$ transformer is used with output voltage of 9v.There also used four IN4007 diodes for making bridge rectifier. Bridge rectifier also used to convert AC to DC supply. There used capacitor $(1000 \mu \mathrm{F})$ to minimize the ripple voltage and smooth the DC voltage.

\section{METHODOLOGY}

Microcontroller based control circuit of wieper need software to clean dust on the solar panel.It can be written by BASCOM compiler. At first we initialize the PINB.0-PINB.2 as input and PORTD.0-PORTD.3, PORTC as output. The TIME\$ variable can be used in combination with the CONFIG CLOCK and CONFIG DATE directive. The CONFIG CLOCK statement will use the TIMER0 or TIMER2 in async mode to create a 1 second interrupt. In this interrupt routine the _Sec, _Min and _Hour variables are updated. PINB.1 and PINB. 2 represents the controls switches for minute and second respectively. The time format of the clock is 24 hour format .Software check that the time is 5:30 A.M.if it is 5:30 A.M then it wiep two times on the solar panel if not it does not anything.we use a key for wiep anytime.if those key press anyone then PINB.0 get $5 \mathrm{v}$ and weiper weipe on the solar panel.

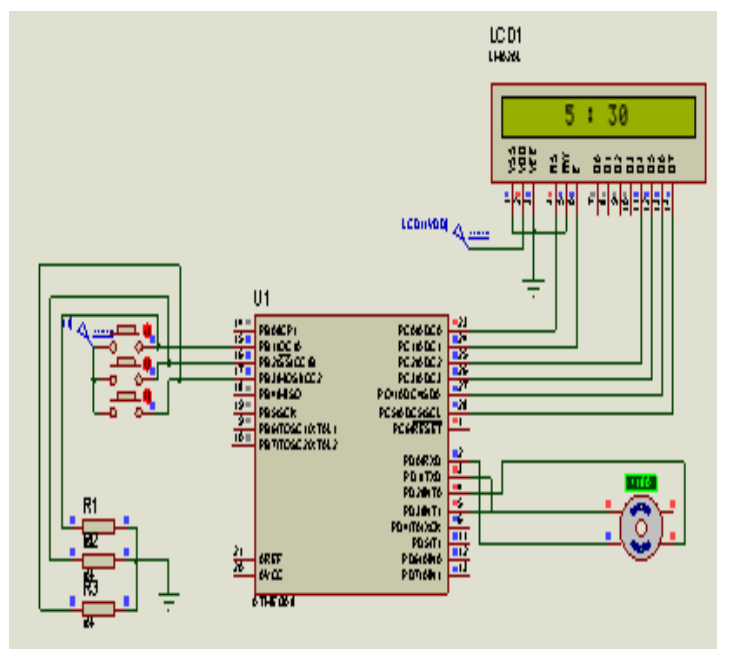

Fig 16. Proteous simulation of Proposed Idea

\section{ADVANTAGES OF OUR PROPOSED DEVICE}

1. There is no need of microcontroller if charge controller is microcontroller based charge controller.

2. It takes power from the solar panel.

3. It is an automated control device.

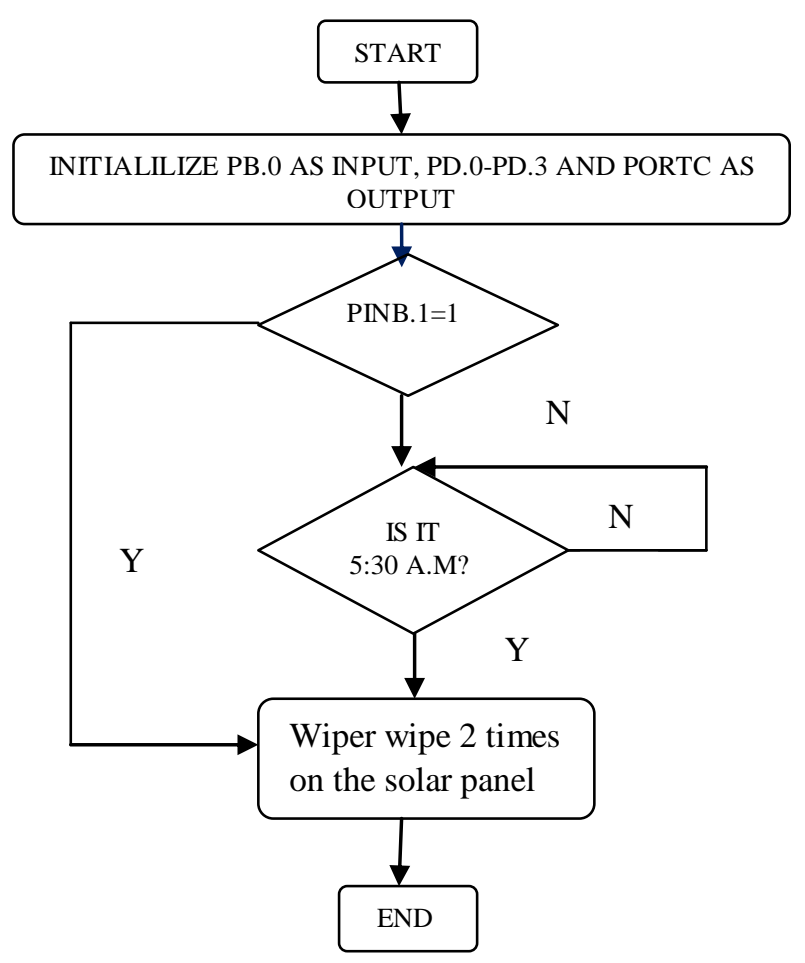

Fig 17. Flow chart of software

\section{CONCLUSIONS}

Solar Energy is one of the most important energy sources of the present world. With the development of technology for a modern life, especially for running the industries, transportation, domestic appliances, agriculture, health, education and research, food storage and transportation, and recreation etc., demand for energy is experienced at an increasing rate. The major sources of energy, especially, the fossil fuels have alarmingly depleted and the world stands at the brisk of great energy crisis. Moreover, burning fossil fuels has resulted in global warming, climate change and ecological damage putting the planet in great danger.[7] The effect of presence of dust was studied using natural dust under the sun. Dust has an effect on the performance of solar PV panel. The reduction in the peak power generated can be up to $20 \%$. It was also shown that under greater irradiation, the effect of dust became slightly reduced but not negligible. Hence, in practice, dust must be removed from the surface of solar PV panel in order to ensure highest performance, given the fact that it is still a costly form of energy source and the short lifespan it has.So,we hope that our proposed idea is unique and helpful to maintain the good power level of solar panel. 


\section{REFERENCES}

[1] http://www.atmel.com

[2] Chetan Singh Solanki, RENEWABLE ENERGY TECHNOLOGIES: A Practical Guide for Beginners, $3^{\text {rd }}$ edition, PHI Learning private limited, October 2009

[3] Solar Power Information (2009, 8 April 2011). Solar Panels. Available: www.solarpower2day.net/solar-panels/.

[4] Shaharin A. Sulaiman, Haizatul H. Hussain, Nik Siti H. Nik Leh, and Mohd S. I. Razali," Effects of Dust on the Performance of PV Panels" in World Academy of Science, Engineering and Technology, 58, 2011,p.p:588-593

[5] Rizwan ur Rahman, Dewan Ishtiaque Ahmed, Mufrad Ahmed Fahmi, Tithi Tasnuva, Md. Fayyaz Khan, "Performance Enhancement of PV Solar System by Diffused Reflection," in 1st International Conference on the Developments in Renewable Energy Technology (ICDRET 2009), pp. 96-99, Dhaka, Bangladesh, December 17-19, 2009, ISBN 978-984-33-0616-6

[6] A. Salim, F. Huraib, and N. Eugenio, " PV powerstudy of system options and optimization," in Proceedings of the 8th European PV SolarEnergy Conference, Florence, Italy, 1988.

[7] A. Ibrahim ,"Effect of Shadow and Dust on the Performance of Silicon Solar Cell" in J. Basic. Appl. Sci. Res., 1(3)222-230, 2011

[8] Theerawut Jinayim, Somchai Arunrungrasmi, Tanes Tanitteerapan, and Narong Mungkung "Highly Efficient Low Power Consumption Tracking Solar Cells for White LED-Based Lighting System in 'World Academy of Science, Engineering and Technology', vol. 1 no.2 pp.126131,winter 2007.

[9] F. Wakim, "Introduction of PV power generation to Kuwait," Kuwait Institute for Scientific Researchers, Kuwait City, 1981.
Md. Mizanur Rahman. Now he is studying in EEE department (4th year 2nd semester) at University of Asia Pacific House No.73, Road No.5A, Dhanmondi ,Dhaka,1209, Bangladesh.

Md. Aminul Islam. Now he is studying in EEE department (4th year 1st semester), University of Asia Pacific (UAP)House No.73, Road No.5A, Dhanmondi, Dhaka1209, Bangladesh

A.H.M. Zadidul Karim. Assistant Professor, Department of Electrical and Electronic Engineering (EEE),University of Asia Pacific (UAP) House No. 73, Road No. 5A, Dhanmondi, Dhaka 1209, Bangladesh

Asraful Haque Ronee. Now he is studying in EEE department (4th year 2nd semester) at University of Asia Pacific House No.73, Road No.5A, Dhanmondi Dhaka. Bangladesh. 